\title{
Rate of cardiac arrhythmias and silent brain lesions in experienced marathon runners: rationale, design and baseline data of the Berlin Beat of Running study
}

Karl Georg Haeusler ${ }^{1,2^{*}}$, Juliane Herm², Claudia Kunze ${ }^{2}$, Matthias Krüll ${ }^{3,4}$, Lars Brechtel ${ }^{3,4,5}$, Jürgen Lock ${ }^{3,4}$, Marc Hohenhaus ${ }^{2}$, Peter U Heuschmann ${ }^{2,6}$, Jochen B Fiebach ${ }^{2}$, Wilhelm Haverkamp ${ }^{7}$, Matthias Endres ${ }^{1,2,8}$ and Gerhard Jan Jungehulsing ${ }^{1,2}$

\begin{abstract}
Background: Regular exercise is beneficial for cardiovascular health but a recent meta-analysis indicated a relationship between extensive endurance sport and a higher risk of atrial fibrillation, an independent risk factor for stroke. However, data on the frequency of cardiac arrhythmias or (clinically silent) brain lesions during and after marathon running are missing.

Methods/ Design: In the prospective observational "Berlin Beat of Running" study experienced endurance athletes underwent clinical examination (CE), 3 Tesla brain magnetic resonance imaging (MRI), carotid ultrasound imaging (CUI) and serial blood sampling (BS) within 2-3 days prior (CE, MRI, CUI, BS), directly after (CE, BS) and within 2 days after (CE, MRI, BS) the $38^{\text {th }}$ BMW BERLIN-MARATHON 2011. All participants wore a portable electrocardiogram (ECG)-recorder throughout the 4 to 5 days baseline study period. Participants with pathological MRI findings after the marathon, troponin elevations or detected cardiac arrhythmias will be asked to undergo cardiac MRI to rule out structural abnormalities. A follow-up is scheduled after one year.
\end{abstract}

Results: Here we report the baseline data of the enrolled 110 athletes aged 36-61 years. Their mean age was $48.8 \pm 6.0$ years, $24.5 \%$ were female, $8.2 \%$ had hypertension and $2.7 \%$ had hyperlipidaemia. Participants have attended a mean of $7.5 \pm 6.6$ marathon races within the last 5 years and a mean of $16 \pm 36$ marathon races in total. Their weekly running distance prior to the $38^{\text {th }}$ BMW BERLIN-MARATHON was $65 \pm 17 \mathrm{~km}$. Finally, 108 (98.2\%) Berlin Beat-Study participants successfully completed the 38 ${ }^{\text {th }}$ BMW BERLIN-MARATHON 2011.

Discussion: Findings from the "Berlin Beats of Running" study will help to balance the benefits and risks of extensive endurance sport. ECG-recording during the marathon might contribute to identify athletes at risk for cardiovascular events. MRI results will give new insights into the link between physical stress and brain damage.

Trial registration: clinicaltrials.gov NCT01428778

Keywords: Marathon running, ECG-recording, Magnetic resonance imaging, Blood sampling, Cardiac arrhythmia

\footnotetext{
* Correspondence: georg.haeusler@charite.de

'Department of Neurology, Charité Berlin Campus Benjamin Franklin,

Hindenburgdamm 30, 12203, Berlin, Germany

${ }^{2}$ Center for Stroke Research University Medicine Berlin, Campus Benjamin

Franklin, Hindenburgdamm 30, Berlin 12203Charité, Germany

Full list of author information is available at the end of the article
} 


\section{Background}

Regular physical exercise is becoming more and more popular in modern societies. Besides reflecting a healthy life style, endurance sport is beneficial for cardiovascular health [1,2], and lowers the risk of cancer [3] or mood disorders [4]. With regard to the increasing number of marathon runners in recent years, it remains an open question whether vigorous physical exercise, such as marathon running, might have harmful effects on heart and brain.

One might argue that sudden cardiac deaths occur rarely in marathon runners [5] despite of the fact that regular physical activity reduces the risk of coronary events during exercise [6]. Moreover, right ventricular dysfunction [7] and troponin elevations are common during marathon running, but these transient effects do not appear to cause cardiac ischemic injury $[8,9]$. However, a recent meta-analysis of mostly retrospective, small case-control series indicated that intense endurance sport increases the long-term risk of atrial fibrillation (AF) [10], while the underlying mechanisms and the impact of higher levels of physical exercise are poorly understood [11,12]. These findings raised concerns and afford further investigation because individuals with (even paroxysmal) AF have a four- to fivefold increased risk of ischemic stroke $[13,14]$. Moreover, clinically silent strokes frequently occur in AF-patients [15] and contribute to cognitive decline in the long-term [16].

The identification of endurance athletes at risk for cardiovascular events is challenging and despite of existing recommendations for medical screening in athletes $[17,18]$, there is an ongoing debate about efficacy of routine screening and the impact of false-positive results [19]. Therefore, prospective studies are needed to characterize the preventive value of cardiac monitoring $[20,21]$. In particular, eligible data on the frequency of $\mathrm{AF}$ and other cardiac arrhythmias during endurance sport are missing so far [22]. Moreover, the frequency of (clinically silent) brain lesions during endurance sport is unknown. However, there are case reports on hyponatremic encephalopathy [23] and on non-significant changes of brain specific biomarkers [24], indicating potential brain damage during a marathon race.

To answer these questions, we initiated the prospective and observational "Berlin Beat of Running" study. By using a continuous ECG-monitoring we focus on the frequency of (clinically silent) cardiac arrhythmias in healthy endurance athletes before, during and after the $38^{\text {th }}$ BMW BERLIN-MARATHON 2011. By conducting MRI measurements at 3 Tesla (T) and serial laboratory tests immediately before and after the marathon race we hope to set new standards for further studies in endurance athletes.

\section{Methods / Design}

\section{Study population and study design}

The "Berlin Beat of Running" study is a prospective, observational, investigator-initiated study conducted by the Center for Stroke Research Berlin, Charité Berlin in cooperation with the Department of Cardiology, Charité (Campus Virchow-Klinikum), and the Medical Institute "SMS Sports Medicine Berlin" of the BMW BERLINMARATHON. The BMW BERLIN-MARATHON is one of the world's largest marathons and more than 42.000 runners took part in 2011 (www.bmw-berlin-marathon.com). The "Berlin Beat of Running" study protocol is in accordance with the Helsinki declaration and was approved by the local Ethics Committee (EA4/042/11). Recruitment of athletes was supported by the SCC EVENTS GmbH (Sporting Club Charlottenburg, SCC), the organizer of the $38^{\text {th }}$ BMW BERLIN-MARATHON. Study entry and storage of data required subsequent consent by the participants. The inclusion and exclusion criteria are summarized in Table 1.

Baseline visit was done within three days before the $38^{\text {th }}$ BMW BERLIN-MARATHON. After informed consent, sociodemographics, the prevalence of cardiovascular risk factors, and the level of physical activity were assessed. Participants underwent assessment of vital parameters (heart rate and blood pressure), neurological examination (NIHSS score [25]) and venous blood sampling (complete blood cell count, ions, cardiac enzymes, renal function, neuron-specific enolase, endothelial markers, i.e. circulating endothelial microparticles, sICAM, Endothelin-1 and VEGF). The intima-media thickness was measured by using B-mode ultrasound (Esaote Mylab 25, ESAOTE Biomedica Deutschland $\mathrm{GmbH}$, Köln, Germany) [26]. Brain MRI at $3 \mathrm{~T}$ was

Table 1 The "Berlin Beat of Running" study: Inclusion and exclusion criteria

Inclusion criteria

- Preregistered participant of the $38^{\text {th }}$ BMW BERLIN-MARATHON 2011

- Age $\geq 35$ and $\leq 60$ years

- Marathon history: at least 2 marathon runs within the last 5 years

- Amount of physical activity: running for at least $40 \mathrm{~km}$ per week

- Sinus rhythm on the day of enrolment

\section{Exclusion criteria}

- Known cardiac disease or cardiac arrhythmia

- Known stroke or TIA, brain tumour or infectious disease affecting the brain

- Contraindications for magnetic resonance imaging

- Acute cerebral infarction or other clinical relevant pathological findings detected by brain magnetic resonance imaging before the marathon

- Severe liver or kidney disease

- Hyperthyroidism, pregnancy or lactation 
performed (see below). Finally, a portable ECG-recorder (CardioMem $^{\circledR}$ CM 4000; GETEMED AG, Teltow, Germany; see below) was mounted by using five chest electrodes and ECG-recording was started. On marathon day, all remaining participants attended the study team within two hours before the start to ensure proper ECG-recording during the race. Within 30 minutes after the end of the marathon race vital parameters were assessed, and a second blood sampling (parameters as stated above) was done. ECG-recording was continued after the marathon race until the second brain MRI was done (within 20-58 hours after the end of the $38^{\text {th }}$ BMW BERLIN-MARATHON 2011). Afterwards the third blood sampling (parameters as stated above), assessment of vital parameters, neurological examination and Holter recording was done at the Charité.

All participants with detected atrial fibrillation, MRIdetected ischemic stroke or troponin elevation will undergo contrast-enhanced cardiac MRI. Participants with new brain lesions after the marathon will undergo additional brain MRI three months after the second brain MRI. Regular follow-up of all participants will take place 12 months after the marathon and will include an additional long-term ECG-recording. The final results of "Berlin Beat of Running" study are expected at the end of the year 2012 .

\section{Aims and objectives}

The aims of this "Berlin Beat of Running" study are: (1) to identify the frequency of cardiac arrhythmias in experienced marathon runners; (2) to become aware of impact factors associated with cardiac arrhythmias; (3) to analyse the frequency of (clinically silent) MRIdetected brain lesions before and immediately after a marathon race; (4) to correlate pathological findings of heart and brain to laboratory results; (5) to rule out myocardial scars in athletes with elevated troponin levels after the marathon; (6) to demonstrate feasibility of valid ECG-recording during enduring sports.

The primary hypothesis of the "Berlin Beat of Running" study is: (1) Cardiac arrhythmia and especially AF is frequently found in experienced marathon runners. Therefore, the primary outcome is the number of marathon runners with newly diagnosed cardiac arrhythmias. Secondary hypothesis are: (2) There are predictable risk factors associated with cardiac arrhythmias in marathon runners. (3) Marathon running is associated with (clinical silent) brain lesions, especially in those athletes with cardiac arrhythmias. The corresponding outcome parameter is the number of marathon runners with newly diagnosed brain lesions according to $3 \mathrm{~T}$ MRI after the marathon race. (4) Pathological laboratory findings are in part associated with cardiac arrhythmias and MRI findings of heart and brain. (5) Marathon runners with elevated troponin levels do not have MRIdetected myocardial scars suggestive for myocardial infarction. The corresponding outcome parameter will be assessed by using a contrast-enhanced cardiac MRI in participants with troponin elevation after the marathon race. Primary feasibility endpoint is the ability of the participants to complete the marathon despite of wearing the ECG-recorder.

\section{MRI analysis}

Using a 3 T MR scanner (Magnetom Tim Trio; Siemens AG, Erlangen, Germany) the following sequences were done within 22-74 hours before as well as 20-58 hours after the marathon race: $\mathrm{T} 2 \%$-weighted imaging to screen for intracranial hemorrhage; diffusion-weighted imaging (DWI) to assess cerebral infarction and/or vasogenic oedema; Fluid-attenuated inverse recovery (FLAIR) to estimate microangiopathic lesions load and to investigate the age of recent lesions; time-of-flight MR-Angiography (TOF MRA) to detect vessel stenosis or occlusion [27]. Three month after the marathon a further measurement will be performed in those athletes with (clinically silent) brain lesions. Athletes with (clinically silent) brain lesions, cardiac arrhythmias or relevant troponin elevations will be asked to undergo cardiac 3 T MRI (Magnetom Tim Trio; Siemens AG, Erlangen, Germany) with a phased array receiver coil during breath-holds gated to the electrocardiogram (Body Matrix-coil \#TATS; Siemens AG). Cine images of 3 long-axis as well as 14-18 short-axis views (slices of $4 \mathrm{~mm}$ ) using a steady state free precession technique [28]. Eight minutes after i.v. administration of 10-12 ml Gadovist $^{\circledR}$ (Bayer Schering Pharma AG, Berlin, Germany) at a concentration of $1 \mathrm{mmol} / \mathrm{ml}$ the above mentioned views will be repeated using a short inversion recovery sequence continuously adjusting the inversion time [29]. Blinded MRI reading will be done by a board certified (neuro-)radiologist (JBF).

\section{ECG-recording}

The portable CardioMem ${ }^{\circledR}$ CM 4000 (GETEMED AG, Teltow, Germany) is a 5-lead, high-resolution digital Holter ECG-recorder, which performs continuous ECGrecording up to five days without changing the battery. Commercial electrodes (Blue Sensor SP; Ambu Inc, Glen Burnie, Maryland, USA) were placed in standard positions and fixed with additional tape. Acquired ECG-data were stored on the integrated memory card and transferred to a PC via the Hi-Speed USB interface. The analyses provided by the Holter system CardioDay ${ }^{\circledR}$ (GETEMED AG) includes heart rate, heart rate variability, ST-analysis, detection of atrial fibrillation as well as additional specialised tools such as heart rate turbulence, deceleration capacity and T-wave alternans 
(GE Healthcare, Milwaukee, WI, USA). ECG-reading and interpretation was performed off-line by an experienced physician.

\section{Sample size calculation and statistical analysis}

The precision analysis is based on 100 ECG-monitored marathon runners. We hypothesize an odds ratio of 5.3 for atrial fibrillation in marathon runners compared to the normal population [10]. Assuming an AFprevalence of $1 \%$ to $2 \%$ within the general population [30], this would correspond to an AF-prevalence between $5.1 \%$ and $9.8 \%$ in marathon runners. We intend to use the Wilson confidence interval as a basis, because we anticipate good properties regarding expected confidence interval length and coverage probability over a broad range for actual rates. First scenario: General AF-prevalence of $1 \%$ in the normal population: A sample size of 100 will provide a two-sided $95 \%$ confidence interval with a width equal to 0.091 with lower limit 0.022 and upper limit 0.113 when the sample proportion for marathon runners is 0.051 . Second scenario: General AF-prevalence of $2 \%$ in the normal population: A sample size of 100 produces a two-sided $95 \%$ confidence interval with a width equal to 0.118 with lower limit 0.054 and upper limit 0.172 when the sample proportion for marathon runners is 0.098. Furthermore, we will report the proportion of (clinically silent) brain lesions within the group of marathon runners during the race. Due to the expected low number of events, it seems to be not feasible to compare the observed proportion for silent ischemic stroke statistically. Assuming a drop out rate of $10 \%$, we included 110 marathon runners.

Descriptive statistics will be done regarding the outcome variables. For quantitative data, we will compute absolute and relative frequencies. In the case of continuous or quasi-continuous variables with nearly symmetric distribution, we will compute arithmetic mean, standard deviation, minimal and maximal values, otherwise median, quartiles, minimal and maximal values. Fisher's exact test will be used to compare proportions for dichotomous outcomes between independent groups or to test independency of two dichotomous data within a population. Ordinal scaled outcomes will be compared by the t-test or the Mann-Whitney test, respectively, depending on normality or non-normality of distribution. The data presented here have been analyzed accordingly.

\section{Results}

\section{Baseline characteristics of study participants}

Overall, 110 athletes aged 36-61 years were enrolled (Table 2). Mean age was $48.8 \pm 6.0$ years, $24.5 \%(n=27)$ were female, $8.2 \%(n=9)$ had hypertension, and $2.7 \%$ $(\mathrm{n}=3)$ had hyperlipidaemia. Before the $38^{\text {th }}$ BMW
BERLIN-MARATHON 2011, the participants attended a mean of $7.5 \pm 6.6$ (range 2-50) marathon races within the last 5 years and a mean of $16.1 \pm 35.8$ (range 2-359) marathon races in total. Their average weekly running distance prior to the race was $64.7 \pm 17.3 \mathrm{~km}$ (range 40$120 \mathrm{~km})$. In addition, $45.5 \%(\mathrm{n}=50)$ of the enrolled participants regularly cycle and $18.2 \%(\mathrm{n}=20)$ regularly swim. Besides a lower body mass index and a lower systolic blood pressure in women, there were no genderspecific differences (Table 2).

One participant had to be excluded due to brain MRI findings. Overall, 109 (99.1\%) of all 110 participants took part and 108 (98.2\%) participants finished the $38^{\text {th }}$ BMW BERLIN-MARATHON 2011 in $249 \mathrm{~min} \pm 43 \mathrm{~min}$ in average. One participant quitted the marathon race due to muscular cramps after 34 kilometres but attended all regular study visits.

\section{Discussion}

Regular physical activity improves the cardiovascular risk profile and lowers the overall mortality [11]. However, recent reports gave reasons to question the benefit of vigorous exercise, but there is little evidence from prospective studies so far $[10,12]$. Performing the "Berlin Beat of Running" study, we focus on safety aspects of marathon running by analyzing the frequency of (clinically silent) cardiac arrhythmias as well as of brain lesions in healthy endurance athletes running a marathon. This is the first approach in such a cohort using feasible longtime ECG-recording and high-resolution DWI at $3 \mathrm{~T}$. As demonstrated before [31], high-resolution DWI is able to reveal about twice as many cerebral lesions compared to standard DWI by higher spatial resolution and improved signal-to-noise ratio. In addition, MRI at $3 \mathrm{~T}$ enables a much higher contrast-to-noise ratio, thereby improving diagnostic reliability of stroke detection, while the detection of cerebral haemorrhage, chronic lesions and brain vessel occlusion is at least equal to $1.5 \mathrm{~T}$ MRI [32]. Using the portable ECG-recorder CardioMem ${ }^{\circledR}$ CM 4000 we will be able to correlate the rate of brain lesions with the burden of cardiac arrhythmias. The CardioMem $^{\circledR}$ CM 4000 was successfully tested by a few athletes during the $37^{\text {th }}$ real,- BERLIN-MARATHON 2010 [GETEMED AG, Teltow, Germany; personal communication]. So far there is only one comparable study done back in 1994. Luurila et al. monitored the ECG of 37 healthy middle-aged men during a ski marathon in Finland. They reported ST-segment elevations in a few participants during the ski marathon, an increasing number of ventricular premature complexes but no clinically relevant cardiac arrhythmias [22].

Contrast-enhanced cardiac MRI in selected patients will enable us to assess pathological changes in the heart of those participants with brain lesions or cardiac 
Table 2 Baseline characteristics of the "Berlin Beat of Running" cohort $(n=110)$

\begin{tabular}{|c|c|c|c|c|}
\hline & Total & Female & Male & $\mathrm{p}$ \\
\hline & $n=110$ & $\mathbf{n}=\mathbf{2 7}$ & $\mathrm{n}=83$ & \\
\hline Age; years; mean (SD) & $48.8(6.0)$ & $48.8(5.8)$ & $48.8(6.1)$ & 0.939 \\
\hline Age $\geq 50$ years; $\%(n)$ & $40.0(44)$ & $40.7(11)$ & $39.8(33)$ & 0.928 \\
\hline \multicolumn{5}{|l|}{ Physical activity } \\
\hline Marathon runs $\leq 5$ years; mean (SD) & $7.5(6.6)$ & $5.8(3.3)$ & $8.0(7.3)$ & 0.235 \\
\hline Marathon runs total; mean (SD) & $16.0(35.8)$ & $10.0(7.9)$ & $18.0(40.8)$ & 0.247 \\
\hline Current weekly running; km; mean (SD) & $64.8(17.3)$ & $60.2(12.4)$ & $66.1(18.4)$ & 0.207 \\
\hline Regular weekly running; km; mean (SD) & $42.3(13.6)$ & $39.4(11.9)$ & $43.2(14.1)$ & 0.207 \\
\hline Systolic BP*; mmHg; mean (SD) & $127.8(12.9)$ & $122.8(9.0)$ & $129.5(13.6)$ & 0.016 \\
\hline Diastolic BP*; mmHg; mean (SD) & $83.7(8.4)$ & $81.7(9.0)$ & $84.4(8.1)$ & 0.327 \\
\hline Pulse; 1/min; mean (SD) & $61.1(8.2)$ & $61.9(8.2)$ & $60.9(8.2)$ & 0.777 \\
\hline $\mathrm{BMI}^{\S} ; \mathrm{kg} / \mathrm{m}^{2} ;$ mean (SD) & $23.2(2.2)$ & $22.2(2.3)$ & $23.5(2.0)$ & 0.004 \\
\hline NIHSS" score; mean (SD) & $0(0)$ & $0(0)$ & $0(0)$ & 1.000 \\
\hline \multicolumn{5}{|l|}{ Comorbidities; \% (n) } \\
\hline Hypertension & $8.2(9)$ & $0(0)$ & $10.8(9)$ & 0.074 \\
\hline Diabetes mellitus & $0(0)$ & $0(0)$ & $0(0)$ & 1.000 \\
\hline Heart failure & $0(0)$ & $0(0)$ & $0(0)$ & 1.000 \\
\hline Coronary artery disease & $0(0)$ & $0(0)$ & $0(0)$ & 1.000 \\
\hline Hyperlipidaemia & $2.7(3)$ & $0(0)$ & $3.6(3)$ & 0.317 \\
\hline Alcohol abuse; \% (n) & $0(0)$ & $0(0)$ & $0(0)$ & 1.000 \\
\hline Current smoking; \% (n) & $6.4(7)$ & $3.7(1)$ & $7.2(6)$ & 0.515 \\
\hline
\end{tabular}

* Blood pressure; ${ }^{\S}$ Body Mass Index; ${ }^{\#}$ National Institutes of Health Stroke Scale.

arrhythmias [33]. Moreover, (subclinical) myocardial infarction can be ruled out in those patients with troponin elevation after the marathon [34]. Serial laboratory tests will allow drawing conclusions regarding the relationship between exercise and endothelial function, dehydration, renal function or the release of brain-specific biomarkers, respectively. Performing an echocardiogram or cardiac MRI on all participants would have added valuable information to the study. However, due to time restrictions, cardiac imaging was restricted to selected participants with pathological ECG findings or significant troponin elevation during the marathon race.

The data presented here arise from the initial clinical visit immediately before the $38^{\text {th }}$ BMW BERLINMARATHON 2011. Not surprisingly, the data indicate a very low cardiovascular risk profile in study participants further suggesting a low risk for cardiac arrhythmias per se.

As depicted in Table 2, our data will allow comparisons across gender, which are missing so far [10]. Further major advantages of the "Berlin Beat of Running" study are the high technical standard, and the homogeneous cohort of experienced endurance runners without known cardiac arrhythmia. However, the "Berlin
Beat of Running" study has some limitations. First, focusing on experienced marathon runners, we are unable to address questions regarding those athletes running their first marathon or those athletes who are insufficiently trained to run a marathon. Second, due to logistic reasons, the number of participants was limited. Third, ECG-recording during the marathon might be difficult to interpret because of movement artefacts. Fourth, regarding the frequency of cardiac arrhythmias in marathon runners a concurrent "non-athletic" control group might be useful.

Taken together, the "Berlin Beat of Running" study is a prospective observational study in experienced marathon runners. The results will provide further information on the effects of vigorous physical activity on heart and brain and will help to better counsel endurance athletes regarding the risks and benefits of marathon running.

\section{Abbreviations}

AF: Atrial fibrillation; ECG: Electrocardiogram; MRI: Magnetic resonance imaging; T: Tesla.

\section{Competing interests}

KGH reports lecture fees from Sanofi and Bayer Healthcare. MK reports receiving consulting, lecture and advisory board fees from Novartis, Takeda, MSD, GlaxoSmithKline and Janssen-Cilag. JBF reports receiving consulting, lecture and advisory board fees from BMS, Siemens, Philips, Perceptive, Bio- 
Imaging Technologies, Boehringer Ingelheim, Lundbeck and Sygnis. ME reports consulting, lecture, grant and/ or advisory board fees from BMS, Sanofi, Boehringer-Ingelheim, Novartis, Pfizer and AstraZeneca. GJJ received consulting and lecture fees from Bayer Health Care, Boehringer Ingelheim, Genzyme, Novartis, Pfizer, Sanofi and Takeda.

\section{Authors' contributions}

All authors have read and approved the final manuscript. KGH, GJJ, JH and CK initiated the study. ME, WH, JL, LB and MK added substantially to its final form. KGH, JH and GJJ wrote the study-protocol and the draft of the manuscript. The MRI examinations were primarily done by CK under supervision of JBF, who will do the blinded MRI reading in addition. Data management was primarily done by MH. PUH did and will do the statistical calculations. The assessment of cardiac arrhythmias is supervised by WH.

\section{Acknowledgement}

We appreciate the work of the organizing SCC EVENTS GmbH who supported the "Berlin Beat of Running" study in an outstanding manner. We would like to thank the following members of the "Berlin Beat of Running" study team for their support, help and incredible spirit: Andrea Hassenpflug, Bianca Deparade-Berger, Birgit Bahr, Sarah Eichler, Carsten Ehlert, Sophie Ewald, Diana Franke, Martin Jünemann, Ulrike Kubisch, Thomas Liman, Gaby Nieweler, Johanna Nieweler, Jana Rosinski, Maren Schmiester and Robert Steinicke. We would also like to thank Jane Thümmler (Center for Stroke Research Berlin) for her help in establishing the database and Andrea Schoenknecht (Labor Berlin - Charité Vivantes GmbH) for coordinating the serial laboratory assessment. Moreover, we are thankful for the support provided by Michael Scherf, Christian Klerx and Madeleine Kulick (all members of the GETEMED AG). Finally we want to thank all "Berlin Beat" runners for their participation, their interest in our work and an extraordinary compliance.

\section{Sources of funding}

The investigator-initiated Berlin Beat of Running Study was supported by the SCC EVENTS GmbH, Berlin. Bayer Healthcare and sanofi-Aventis sponsored the study by an unrestricted grant. The GETEMED AG (Teltow, Germany) provided the ECG-recorders and comprehensive technical support. KGH, JH, $C K, J B F, M E$ and GJJ received funding from the Federal Ministry of Education and Research via the grant Center for Stroke Research Berlin (01 EO 0801). ME receives support from the Volkswagen-Stiftung, Deutsche Forschungsgemeinschaft and the EU.

\section{Author details}

'Department of Neurology, Charité Berlin Campus Benjamin Franklin, Hindenburgdamm 30, 12203, Berlin, Germany. ${ }^{2}$ Center for Stroke Research University Medicine Berlin, Campus Benjamin Franklin, Hindenburgdamm 30, Berlin 12203Charité, Germany. ${ }^{3}$ SMS Sports Medicine Berlin, Medical Institute of the BMW BERLIN-MARATHON, Germany. ${ }^{4}$ Berliner Akademie für Sportmedizin e.V, Berlin, Germany. ${ }^{5}$ Department of Sports Medicine, Humboldt-University, Berlin, Germany. Institute of Clinical Epidemiology and Biometry, Center for Clinical Studies and Comprehensive Heart Failure Center, University Hospital, Würzburg, Germany. ${ }^{7}$ Department of Cardiology, Campus Vichow-Klinikum, Berlin Charité, Germany. ${ }^{8}$ Excellence Cluster NeuroCure, Charité - Universitätsmedizin Berlin, Berlin, Germany.

Received: 22 December 2011 Accepted: 1 August 2012

Published: 31 August 2012

\section{References}

1. Mora S, Cook N, Buring JE, Ridker PM, Lee I-M: Physical activity and reduced risk of cardiovascular events: potential mediating mechanisms. Circulation 2007, 116:2110-2118.

2. Endres M, Gertz K, Lindauer U, Katchanov J, Schultze J, Schröck H, Nickenig G, Kuschinsky W, Dirnagl U, Laufs U: Mechanisms of stroke protection by physical activity. Ann Neurol 2003, 54:582-590

3. Winzer BM, Whiteman DC, Reeves MM, Paratz JD: Physical activity and cancer prevention: a systematic review of clinical trials. Cancer Causes Control 2011, 22:811-826.

4. Carek PJ, Laibstain SE, Carek SM: Exercise for the treatment of depression and anxiety. Int J Psychiatry Med 2011, 41:15-28.
5. Redelmeier DA, Greenwald JA: Competing risks of mortality with marathons: retrospective analysis. BMJ 2007, 335:1275-1277.

6. Albert CM, Mittleman MA, Chae CU, Lee IM, Hennekens CH, Manson JE: Triggering of sudden death from cardiac causes by vigorous exertion. $N$ Engl J Med 2000, 343:1355-1361.

7. Oomah SR, Mousavi N, Bhullar N, Kumar K, Walker JR, Lytwyn M, Colish J, Wassef A, Kirkpatrick IDC, Sharma S, Jassal DS: The role of threedimensional echocardiography in the assessment of right ventricular dysfunction after a half marathon: comparison with cardiac magnetic resonance imaging. J Am Soc Echocardiogr 2011, 24:207-213.

8. Trivax JE, Franklin BA, Goldstein JA, Chinnaiyan KM, Gallagher MJ, DeJong AT, Colar JM, Haines DE, McCullough PA: Acute cardiac effects of marathon running. J Appl Physiol 2010, 108:1 148-1153.

9. Knebel F, Schimke I, Schroeckh S, Peters H, Eddicks S, Schattke S, Brechtel L, Lock J, Wernecke KD, Dreger H, Grubitz S, Schmidt J, Baumann G, Borges AC: Myocardial function in older male amateur marathon runners: assessment by tissue Doppler echocardiography, speckle tracking, and cardiac biomarkers. J Am Soc Echocardiogr 2009, 22:803-809.

10. Abdulla J, Nielsen JR: Is the risk of atrial fibrillation higher in athletes than in the general population? A systematic review and meta-analysis. Europace 2009, 11:1156-1159.

11. Mont L, Elosua R, Brugada J: Endurance sport practice as a risk factor for atrial fibrillation and atrial flutter. Europace 2009, 11:11-17.

12. Aizer A, Gaziano JM, Cook NR, Manson JE, Buring JE, Albert CM: Relation of vigorous exercise to risk of atrial fibrillation. Am J Cardiol 2009, 103: 1572-1577.

13. Wolf $\mathrm{PA}$, Abbott RD, Kannel WB: Atrial fibrillation as an independent risk factor for stroke: the Framingham Study. Stroke 1991, 22:983-988.

14. Nieuwlaat R, Dinh T, Olsson SB, Camm AJ, Capucci A, Tieleman RG, Lip GYH, Crijns HJGM: Should we abandon the common practice of withholding oral anticoagulation in paroxysmal atrial fibrillation? Eur Heart J 2008, 29:915-922.

15. Kobayashi A, Iguchi M, Shimizu S, Uchiyama S: Silent Cerebral Infarcts and Cerebral White Matter Lesions in Patients with Nonvalvular Atrial Fibrillation. J Stroke Cerebrovasc Dis. 2012, 21:310-721:310-7

16. Debette $S$, Markus HS: The clinical importance of white matter hyperintensities on brain magnetic resonance imaging: systematic review and meta-analysis. BMJ 2010, 341:c3666.

17. Maron BJ, Douglas PS, Graham TP, Nishimura RA, Thompson PD: Task Force 1: preparticipation screening and diagnosis of cardiovascular disease in athletes. J Am Coll Cardiol 2005, 45:1322-1326.

18. Thompson PD, Franklin BA, Balady GJ, Blair SN, Corrado D, Estes NAM, Fulton JE, Gordon NF, Haskell WL, Link MS, Maron BJ, Mittleman MA, Pelliccia A, Wenger NK, Willich SN, Costa F: Exercise and acute cardiovascular events placing the risks into perspective: a scientific statement from the American Heart Association Council on Nutrition, Physical Activity, and Metabolism and the Council on Clinical Cardiology. Circulation 2007, 115:2358-2368.

19. Corrado D, Schmied C, Basso C, Borjesson M, Schiavon M, Pelliccia A, Vanhees $L$, Thiene G: Risk of sports: do we need a pre-participation screening for competitive and leisure athletes? Eur Heart J 2011, 32: 934-944.

20. Drezner JA: Contemporary approaches to the identification of athletes at risk for sudden cardiac death. Curr Opin Cardiol 2008, 23:494-501.

21. Wheeler MT, Heidenreich PA, Froelicher VF, Hlatky MA, Ashley EA: Cost-effectiveness of preparticipation screening for prevention of sudden cardiac death in young athletes. Ann Intern Med 2010, 152:276-286

22. Luurila OJ, Karjalainen J, Viitasalo M, Toivonen L: Arrhythmias and ST segment deviation during prolonged exhaustive exercise (ski marathon) in healthy middle-aged men. Eur Heart J 1994, 15:507-513.

23. Ayus JC, Varon J, Arieff AL: Hyponatremia, cerebral edema, and noncardiogenic pulmonary edema in marathon runners. Ann Intern Med 2000, 132:711-714.

24. Saenz AJ, Lee-Lewandrowski E, Wood MJ, Neilan TG, Siegel AJ, Januzzi JL, Lewandrowski KB: Measurement of a plasma stroke biomarker panel and cardiac troponin T in marathon runners before and after the 2005 Boston marathon. Am J Clin Pathol 2006, 126:185-189.

25. Brott T, Adams HP, Olinger CP, Marler JR, Barsan WG, Biller J, Spilker J, Holleran R, Eberle R, Hertzberg V: Measurements of acute cerebral infarction: a clinical examination scale. Stroke 1989, 20:864-870. 
26. Rossi AC, Brands PJ, Hoeks APG: Automatic recognition of the common carotid artery in longitudinal ultrasound B-mode scans. Med Image Anal 2008, 12:653-665.

27. Hotter B, Pittl S, Ebinger M, Oepen G, Jegzentis K, Kudo K, Rozanski M, Schmidt WU, Brunecker P, Xu C, Martus P, Endres M, Jungehülsing GJ, Villringer A, Fiebach JB: Prospective study on the mismatch concept in acute stroke patients within the first $24 \mathrm{~h}$ after symptom onset 1000Plus study. BMC Neurol 2009, 9:60.

28. Carr JC, Simonetti O, Bundy J, Li D, Pereles S, Finn JP: Cine MR angiography of the heart with segmented true fast imaging with steady-state precession. Radiology 2001, 219:828-834.

29. Simonetti OP, Kim RJ, Fieno DS, Hillenbrand HB, Wu E, Bundy JM, Finn JP, Judd RM: An improved MR imaging technique for the visualization of myocardial infarction. Radiology 2001, 218:215-223.

30. Camm AJ, Kirchhof P, Lip GYH, Schotten U, Savelieva I, Ernst S, Van Gelder IC, Al-Attar N, Hindricks G, Prendergast B, Heidbuchel H, Alfieri O, Angelini A, Atar D, Colonna P, De Caterina R, De Sutter J, Goette A, Gorenek B, Heldal M, Hohloser SH, Kolh P, Le Heuzey J-Y, Ponikowski P, Rutten FH, Vahanian A, Auricchio A, Bax J, Ceconi C, Dean V, Filippatos G, et al: Guidelines for the management of atrial fibrillation: The Task Force for the Management of Atrial Fibrillation of the European Society of Cardiology (ESC). Eur Heart J 2010, 31:2369-2429.

31. Benameur K, Bykowski JL, Luby M, Warach S, Latour LL: Higher Prevalence of Cortical Lesions Observed in Patients with Acute Stroke Using HighResolution Diffusion-Weighted Imaging. Am J Neuroradiol 2006, 27:1987-1989.

32. Frayne R, Goodyear BG, Dickhoff P, Lauzon ML, Sevick RJ: Magnetic resonance imaging at 3.0 Tesla: challenges and advantages in clinical neurological imaging. Invest Radiol 2003, 38:385-402.

33. Rustemli A, Bhatti TK, Wolff SD: Evaluating cardiac sources of embolic stroke with MRI. Echocardiography 2007, 24:301-308. discussion 308 .

34. Bruder O, Göricke S, Hunold P, Lowitsch M, Barkhausen J, Sabin GV, Forsting M, Fiebach JB: Myocardial scars are an underestimated cardiovascular burden in patients with internal carotid artery stenosis. Cerebrovas Dis 2009, 28:80-87.

\section{doi:10.1186/1471-2261-12-69}

Cite this article as: Haeusler et al:: Rate of cardiac arrhythmias and silent brain lesions in experienced marathon runners: rationale, design and baseline data of the Berlin Beat of Running study. BMC Cardiovascular Disorders 2012 12:69.

\section{Submit your next manuscript to BioMed Central and take full advantage of:}

- Convenient online submission

- Thorough peer review

- No space constraints or color figure charges

- Immediate publication on acceptance

- Inclusion in PubMed, CAS, Scopus and Google Scholar

- Research which is freely available for redistribution 